\title{
TE LO MERECES
}

\section{YOU DESERVE IT}

\section{TU O MERECES \\ Raquel Hernández Blas}

Ganador del Premio Vida y Salud de Narrativa, en su X Edición Modalidad Profesionales y Estudiantes, organizado por el Colegio de Enfermería de Alicante y el Grupo de Investigación Cultura de los Cuidados.

Octubre 2010

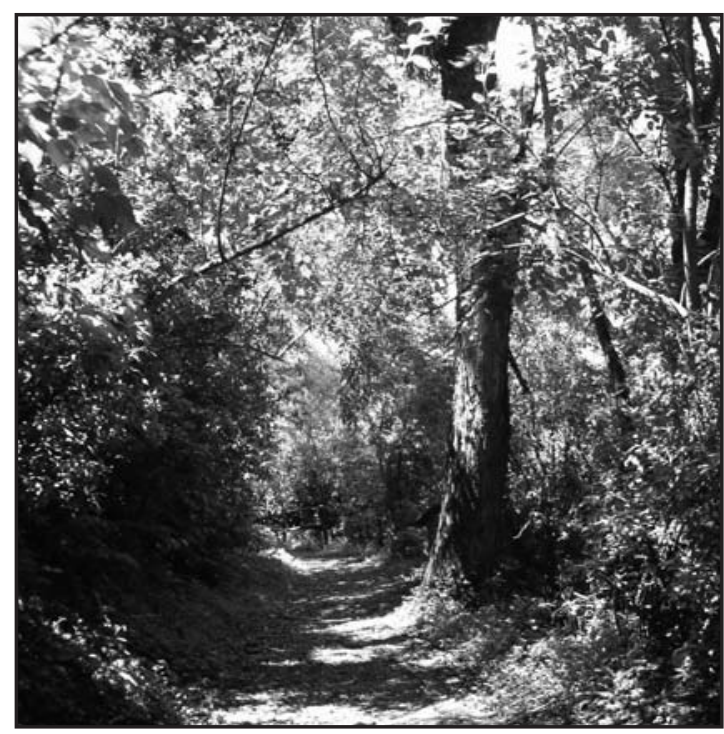

Sabía que necesitaba hacerlo, desde hacía tiempo. Llevaba intentándolo varios meses, me atrevería a decir que incluso años. Quizá no había encontrado la suficiente motivación para decidirme. Seguramente, todo tuvo que ver, todo estuvo relacionado. Me refiero a la metamorfosis que inicié hace ya varios años...

Había dejado de fumar. Nunca hubiera imaginado que esa decisión pudiera llegar a ser un cambio trascendental en mi vida. Más que la propia decisión, quizá fueron más bien las consecuencias que vinieron a continuación, las que dieron fruto a esa catarsis interna, las que modificaron mi trayectoria. Abandonar el tabaco fue "otro" de los resultados del "tomar las riendas de mi vida", como libre auriga, y empezar a timonear el barco a mi antojo, marcando mi propio rumbo.
Dejé de fumar porque... era lo que tocaba, era el siguiente paso, no hacía falta decidirlo, tenía que venir después de llevar viviendo juntos varios años y después de un dilatado período de noviazgo: el siguiente paso, tras haber rechazo el matrimonio en su momento para declararnos formalmente como pareja, era quedarse embarazada. A mis 26 años, viviendo independientes, juntos, con un "buen trabajo" como solía decir mi abuelita, tocaba hacerlo. Y digo tocaba, porque al parecer era lo que todos, (y cuando digo todos no me estoy refiriendo solo a nuestras familias y amigos más allegados, sino al resto del mundo), estaban esperando.

Parece que encontré la gran motivación, la que todos buscamos en algún momento y sólo a veces de forma privilegiada se encuentra, la que me hizo decidirlo de una vez por todas: quise dejar de fumar porque tocaba ser madre. Ahora lo hacía por algo importante, uno de mis proyectos vitales más ambiciosos competía ahora con mi mayor adicción.

Con la alegría de tener la perspectiva de poder conseguirlo, puesto que sabía que esa motivación no iba a desvanecerse como otras lo habían hecho en ocasiones anteriores, y sabiendo que podía recurrir a ella en cualquier momento, incluso en los más difíciles y de mayores deseos, dejé de fumar.

Planifiqué a conciencia el acto: me informé y asesoré al respecto, recabé la suficiente información y cuando decidí que estaba preparada, lo hice. No escogí una fecha (pese a las recomendaciones) ni me deshice de los cigarros que iban en mi bolso en ese momento (o en el bolsillo de mis 
vaqueros). De hecho, permanecieron a mi lado largo tiempo (me propuse que llevar tabaco no tendría por qué ser un obstáculo en mi decisión, ya que la causa por lo que lo hacía era aplastante). Organicé un plan de acción para los momentos más peligrosos: anoté en mi agenda unos consejos y pauté unas medidas para aplicar en los momentos más duros.

Compre chicles y caramelos sin azúcar, que fui depositando en diferentes cajitas y bomboneras por la casa y ubiqué en mis bolsos y en uno de los cajones de mi mesa de trabajo. Durante más o menos veinte días, cambié mi desayuno y mi tan deseado café de después de comer: lo sustituí por un zumo frío de naranja recién exprimida. Este fue uno de los puntos fuertes, puesto que yo no me daba cuenta, pero el tener que preparar el zumo, tanto antes de desayunar como después de comer, distraía a mi deseo de fumar en esos irresistibles momentos. Además, así evitaba ingerir cafeína (confieso que sigo tomando dos cafés al día con leche fría semidesnatada: ¡sublimes!), con lo que evitaba tomar excitantes durante esos primeros días y además, al no tomar el tan arraigado café (muchos años con el mismo hábito) disociaba ese binomio cuasi inseparable café / cigarro. Me resultó bastante útil. Y desde entonces, vivo acompañada del zumo de fruta (antes inexistente en mi dieta).

Durante esos días, me propuse modificar algún que otro comportamiento (como era durante unos días solamente, parecía algo asequible...): me bajaba una parada metro antes y caminaba hasta el trabajo, subía los cuatro pisos hasta mi casa andando. Cambié también mi dieta: me propuse comer "otras cosas". Lo interesante era separar hábitos adquiridos. Me hacía muchas ensaladas (incluso con frutas), usaba todo tipo de verduras y hortalizas, en todas sus modalidades (al horno, a la plancha, al vapor, rehogadas...). Condené la bollería durante la primera etapa (sigue condena$\mathrm{da}$, al menos la industrial, ahora solo tomo la que yo preparo... ¿quién puede resistirse a un bizcocho recién hecho?....) y aumenté la ingesta de líquido (agua o infusiones que guardaba en nevera ya preparadas: buenísimas).

Incluso me planteé ir al gimnasio: ya otras veces lo había hecho y había obtenido resultados (no tengo tiempo, no tengo ganas...). Esta vez fui de 1leno: sabía que si dejaba de fumar iba a aumentar unos cuantos kilos (ya se sabe, erróneamente, que el fumar "adelgaza"), por lo que me saqué un bono de esos que pagas una cantidad fija al mes y puedes luego ir a todas las actividades que quieras. Me iría perfecto; cada día probaría una cosa y ya decidiría cual sería de mi agrado. Tras probar diferentes opciones y pensando en muchos momentos en tirar la toalla y volver a mi vida cómoda y sedentaria, elegí natación y spining (estos los alternaría, para, ya que estaba decidida a tomármelo en serio, moldear ya de paso mi figura y poder trabaja tanto tronco superior como inferior) y danza del vientre, para divertirme y poner el toque de originalidad y porqué no, intriga y sensualidad.

El descubrimiento fue impresionante. A día de hoy (han pasado ya 6 años), sigo coqueteando con la natación, continuo dando clases de danza del vientre, además animé a mi hermana y vamos juntas (este año hemos participado en una actuación ante público, para mí ya la segunda... ii indescriptible!!) y paseo en bici cuando hace buen tiempo y alguien (casi siempre... “él") está dispuesto a acompañarme.

He de decir que en el gimnasio descubrí una parte de mí misma que creía inexistente y obsoleta (una parte lejana, casi infantil, con la que uno vuelve a disfrutar de pequeñas cosas que parecen perdidas), además de un montón de amigos y amigas, personas con vidas paralelas, similares, con iguales inquietudes que yo aunque con diferentes puntos de vista.

Uno de los peores momentos del abandono del tabaco era "el después de las comidas": daba igual la hora, cada vez que ingería alimentos (aunque fuera un simple picoteo, un tentempié) deseaba fumar. Me propuse una actividad (la más trascendental en esta historia): compré un diario y decidí escribir mis pensamientos e ideas, los pensamientos e ideas que abordan e invaden la cabeza en esos momentos de extrema necesidad y tensión de cuando uno "necesita" fumar. Cada vez que me abordaba la necesidad, las ganas de fumar, sacaba el diario, cogía mi bolígrafo (el de la suerte, el que siempre llevo como amuleto) y escribía sin censuras mis ideas. Había veces que incluso escribía 
tantas páginas que terminaban doliéndome los dedos de tanto apretar el bolígrafo... Lo llevaba continuamente conmigo: en el bolso, en el trabajo, en las manos cuando acudía a una reunión o coloquio, si iba a una terraza a tomar algo o al restaurante...

Era curioso, mientras lo hacía, difuminaba mis ganas de fumar. Además, tras escribir (ya os digo que a veces muchísimas páginas), me entraba la curiosidad por leerlo y era fantástico descubrir. DESCUBRIRME. Empecé a leer mis palabras. Mis ideas. Mis pensamientos. Empecé a escuchar lo que yo misma me decía. Y, como no podía ser de otra forma, empecé a cambiar....

Hoy, sigo sin fumar. Ya no es uno de mis deseos. Tengo otros muchos, más intensos y satisfactorios, que merecen más la energía y mis recursos qué fumar; ahora me siento absolutamente libre, mis ideas y pensamientos no están perseguidos ni interrumpidos por la eterna necesidad de fumar un pitillo, ahora.... vuelan a su antojo.

Mi pequeña historia poco tiene que ver con la tuya, estoy segura. Dejar de fumar seguramente no ha cambiado mi vida, simplemente, me ha cambiado a mi. El autocuidado es un valor añadido en la vida de cualquier persona. Un ápice de madurez y una inversión de calidad de vida. Cuídate, porque aunque aún no lo sepas, nadie más que tú lo merece

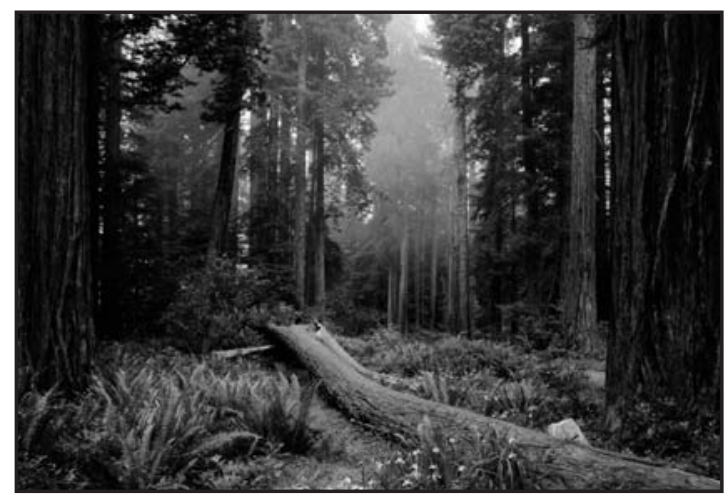

ENTREVISTA A RAQUEL HERNÁNDEZ BLAS ¿Cuál es el principal motivo que te induce a escribir ese relato? ¿Se trata de una autobiografía?

Aunque el relato he referencia a aspectos de una vivencia personal, no podría afirmar que se trate de una autobiografía. Decidí escribir el relato porque me pareció una idea muy bonita, la de poder dar un enfoque a "los cuidados" (en este caso el autocuidado) desde un punto de vista diferente al que estoy acostumbrada por mi profesión, que es la palabra. Es la primera vez que participo en un concurso de relatos y la obtención del premio me ha sorprendido.

\section{¿Qué destacarías del relato?}

Del relato destacaría la simplicidad de la historia y de las palabras utilizadas para contarlo. Creo que la lectura del mismo es sencilla, pero a su vez abarca un complejo y frecuente problema de salud, como es el hábito de fumar y también la difícil posición / decisión ante el mismo que es el intentar dejarlo.

\section{¿Ha transformado esta experiencia personal tu práctica profesional y la interacción con las personas que te relacionas en tu trabajo? ¿Cómo?}

Definitivamente, sí. La decisión de dejar de fumar, por la actitud activa que implica, ha transformado tanto la práctica profesional como la interacción en mi medio de trabajo básicamente porque me ha transformado a mí. El dejar de fumar te posiciona de una manera me atrevería a decir casi que "omnipresente" en el mismo lugar del otro (y no frente a él): te puedes identificar tanto con el fumador, como con el ex fumador, como con la persona que está en la fase de querer dejarlo y no haberlo aún decidido. Eso te posibilita ofrecer ayuda desde un punto de vista diferente, y hace posible poder escuchar al otro, no desde el conocimiento sino desde la experiencia.

\section{¿Piensas que con este tipo de relatos se puede ayudar a los demás?}

Pienso que ayudar a los demás es difícil... lo que sí es útil es intentar utilizar todas las herramientas y opciones posibles para hacerlo, incluso algunas que a priori uno puede no plantearse, como puede ser el escribir un relato. Lo interesante y emocionante para mí es intentar ayudar, aún sabiendo de antemano que no tenemos garantizado conseguirlo. De eso se trata, de no dejar de intentarlo y de continuamente revisar de qué forma estamos haciéndolo, para tratar de mejorarlo. 
¿Cómo has llegado a ser enfermera y a dedicarte a la salud laboral?

Me formé como enfermera después de terminar un ciclo formativo con escasa salida laboral. Tras un período de trabajo de un año en un sector que nada tenía que ver con la salud, sentí no estar haciendo lo que deseaba y decidí matricularme en la Universidad. Después de terminar la universidad, me formé en el campo de Salud Laboral y desde ese momento mi trayectoria profesional ha trascurrido por ese ámbito.

No soy la enfermera vocacional que siempre ha tenido claro a qué se iba a dedicar, al contrario, estudiar enfermería fue "una opción" entre varias en un momento de mi vida, y estoy muy satisfecha con la decisión que tomé, puesto que es una profesión que invita a crecer continuamente.

Finalmente, puedes contarnos ¿cuál es el balance de Raquel, la mujer, la madre y la enfermera después de esta experiencia?

Lo primero, y enlazando con la primera pregunta, decir que no soy madre. El balance del resto de los roles a los que haces referencia en tu pregunta es positivo, por supuesto. Esta experiencia ha contribuido a ese "descubrir" que intento hacer a diario, tanto en lo personal como en lo profesional. Estoy muy contenta con la experiencia porque ha sido muy agradable.

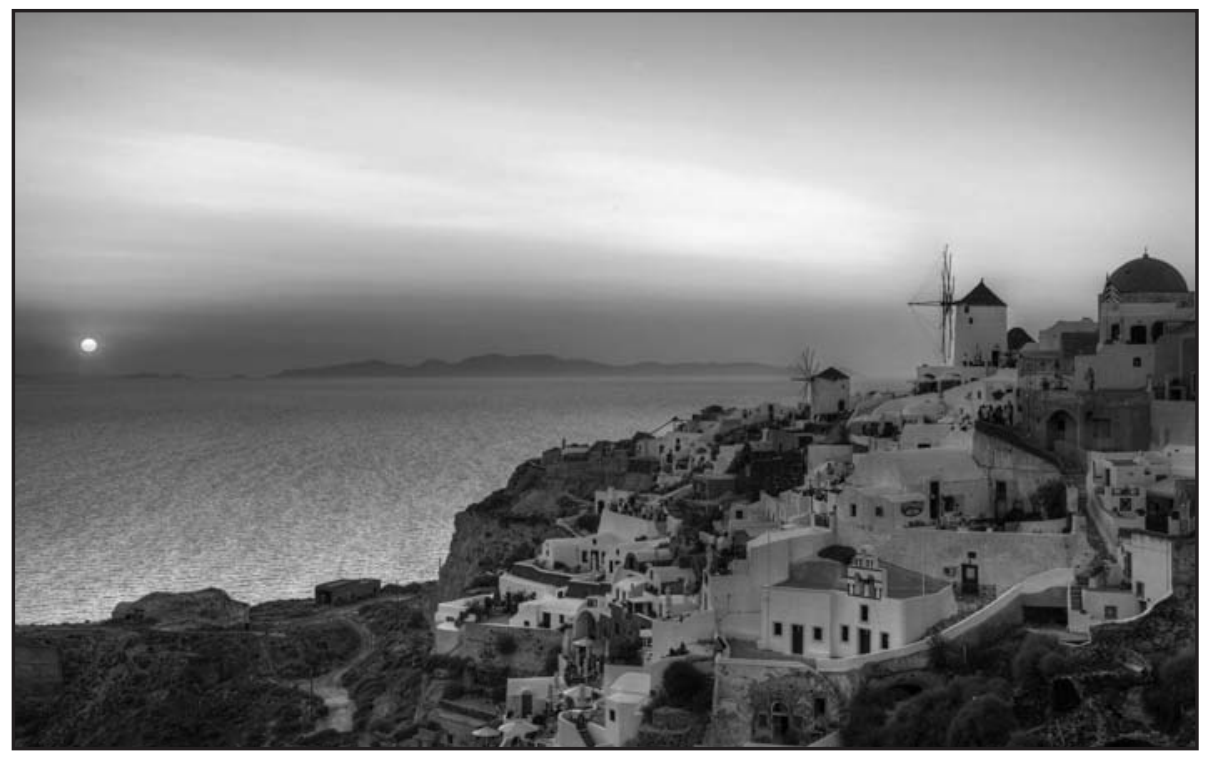

